\title{
Intraoperative assessment of ureter perfusion after revascularization of transplanted kidneys using intravenous indocyanine green fluorescence imaging
}

\author{
Potchara Kanammit $^{1}$, Pokket Sirisreetreerux ${ }^{1} \wedge$, Sarinya Boongird ${ }^{2}$, Suchin Worawichawong ${ }^{3}$, \\ Kittinut Kijvikai ${ }^{1}$
}

${ }^{1}$ Division of Urology, Department of Surgery, Faculty of Medicine Ramathibodi Hospital, Mahidol University, Bangkok, Thailand; ${ }^{2}$ Division of Nephrology, Department of Medicine, Faculty of Medicine Ramathibodi Hospital, Mahidol University, Bangkok, Thailand; ${ }^{3}$ Department of Pathology, Faculty of Medicine Ramathibodi Hospital, Mahidol University, Bangkok, Thailand

Contributions: (I) Conception and design: P Sirisreetreerux, K Kijvikai; (II) Administrative support: S Boongird; (III) Provision of study materials or patients: P Kanammit; (IV) Collection and assembly of data: P Sirisreetreerux; (V) Data analysis and interpretation: P Sirisreetreerux, S Worawichawong; (VI) Manuscript writing: All authors; (VII) Final approval of manuscript: All authors.

Correspondence to: Pokket Sirisreetreerux. Division of Urology, Department of Surgery, Faculty of Medicine Ramathibodi Hospital, Mahidol University, Bangkok 10400, Thailand. Email: pokket.sir@mahidol.edu.

Background: Kidney transplantation is the most valuable renal replacement therapy. One of the most common urologic complications following kidney transplantation is ureter anastomosis leakage, which leads to high morbidity along with kidney graft loss. We hypothesized that indocyanine green (ICG) fluorescence videography can assess ureter perfusion after revascularization of transplanted kidneys.

Methods: We conducted a prospective cross-sectional study in end-stage renal disease patients who underwent deceased donor kidney transplantation at Ramathibodi Hospital from September 2019 to January 2020. The segments of transplanted ureters were categorized as having good or poor perfusion based on the percentage from ICG fluorescence videography images. Then the results from ICG fluorescence videography were compared with histopathology which is considered the gold standard.

Results: Thirty-one sections of dissected ureters were evaluated from 10 patients. Compared with pathological diagnosis of ureteral ischemia, ICG videography had sensitivity, specificity, positive predictive value (PPV), negative predictive value (NPV), and positive likelihood ratio of $100 \%, 92.6 \%, 66.7 \%, 100 \%$, and 14, respectively. Accuracy was $93.6 \%$. The area under the curve of ICG fluorescence videography was 0.96. The average ureter length that maintained good perfusion was $14 \mathrm{~cm}$ from the ureteropelvic junction. Adverse events from ICG were not observed in this study.

Conclusions: We conclude that ICG fluorescence videography is beneficial for detection of early ureteral ischemia in kidney transplantation patients, with negligible adverse events. However, further studies with larger numbers of patients are necessary to confirm our results and clinical outcomes regarding complication rates.

Keywords: Accuracy; fluorescence imaging; indocyanine green (ICG); kidney transplantation; ureter perfusion

Submitted Feb 24, 2021. Accepted for publication Apr 14, 2021.

doi: $10.21037 /$ tau-21-160

View this article at: http://dx.doi.org/10.21037/tau-21-160

^ ORCID: 0000-0002-6900-8356. 


\section{Introduction}

Chronic kidney disease (CKD) ranks among the most common diseases and negatively affects quality of life and life expectancy. Based on the registry from Asian-Pacific, Australian and New Zealand, Canada, Europe, Japan and United States, the prevalence of CKD has increased by $29.3 \%$ since $1990(1,2)$. KT is the most cost-effective procedure for renal replacement therapy which was found to be performed around $69,400 \mathrm{KTs}$ annually worldwide. Among them, 64\% were from deceased donors (3). Compared with dialysis, KT reduces the risk of death by over $60 \%$, doubles expected survival time, and greatly improves quality of life (4).

Urological complications in KT recipients remain common. Complications such as urine leakage, ureteral stenosis, lymphocele, lithiasis, urethral stricture, and vesicoureteral reflux are reported in recipients with incidence of $2.5-30 \%$ (5). One of the most common urologic complications following KT is ureter anastomosis leakage, which leads to high morbidity along with kidney graft loss. At Ramathibodi Hospital, the incidence of urinary leakage complications was reported as roughly $4.4 \%$ (6). Compromising blood supply to the distal ureter during organ procurement is the primary risk factor for ureteral necrosis and urinary leakage, and can lead to high morbidity and kidney graft loss $(7,8)$. Following vascular anastomosis during $\mathrm{KT}$, assessing the quality of the ureter is an important step, although it remains difficult to properly evaluate and can be problematic in some patients. Owing to the anatomical features of the ureter, the branches of its arteries are small and are easily injured because of tearing (9). Currently, no accurate method exists for diagnosing vascular compromise of the ureter, necessitating an attempt to identify a method for assessing the ureter during KT by determining the area of the ureter that has insufficient blood supply before ureter anastomosis is performed $(7,8,10)$.

Indocyanine green (ICG) is widely used for evaluating function and perfusion after various procedures, such as free flap surgery and assessing burn depth (11). The applicability and potential advantages of ICG fluorescence during organ transplantation are limited and incompletely understood. In liver and pancreas transplantations, ICG is used to assess graft bile duct perfusion and the perfusion level of the duodenal graft stump for identifying perfusion defects that may be transected before anastomosis $(12,13)$. Furthermore, fluorescence angiography with ICG allows intraoperative quantitative assessment of delayed graft function during kidney transplantation (14). According to a previous report, the use of ICG fluorescence videography is a valuable adjunctive modality in intraoperative monitoring of free flap surgeries and kidney graft function, and appears to be a sensible tool for detecting compromised microcirculation (15). Because of the basic pharmacokinetic and pharmacodynamic properties of tricarbocyanine dye, most ICG is distributed exclusively in blood vessels. Furthermore, ICG has a short half-life and is rapidly eliminated without enterohepatic and urinary circulation (16). Additionally, images can be obtained relatively quickly using this process. ICG has also been found to induce a low incidence of adverse reactions and is considered safe. However, on the basis of previous studies, information on using ICG primarily for assessing ureteral viability during $\mathrm{KT}$ is limited (17).

With the aim of preventing complications associated with ureteral necrosis, we hypothesized that ICG fluorescence videography could accurately assess ureter perfusion following vascular anastomosis $(11,18)$. The objective of this study was to evaluate the accuracy of ICG fluorescence imaging in the diagnosis of hypoperfusion of transplanted ureters, while comparing it with pathological evidence of ureteral ischemia, which is the gold standard diagnostic method. Because of limited knowledge on the effect of ureteral length on urological complications after KT, our secondary objective was to estimate the average ureter length that maintains good perfusion before performing ureteral reimplantation using fluorescence imaging. Finally, we evaluated the safety of ICG in patients with ESRD. We present the following article in accordance with the STARD reporting checklist (available at http://dx.doi.org/10.21037/ tau-21-160).

\section{Methods}

\section{Study population}

After ethical approval from the Committee on Human Rights Related to Research involving Human Subjects, Faculty of Medicine, Ramathibodi Hospital (No. MURA2018/405), we conducted a cross-sectional study with all ESRD patients who underwent deceased donor kidney transplantation (DDKT) from September 2019 to January 2020. The study was conducted in accordance with the Declaration of Helsinki (as revised in 2013). Inclusion criteria were male and female ESRD patients aged over 


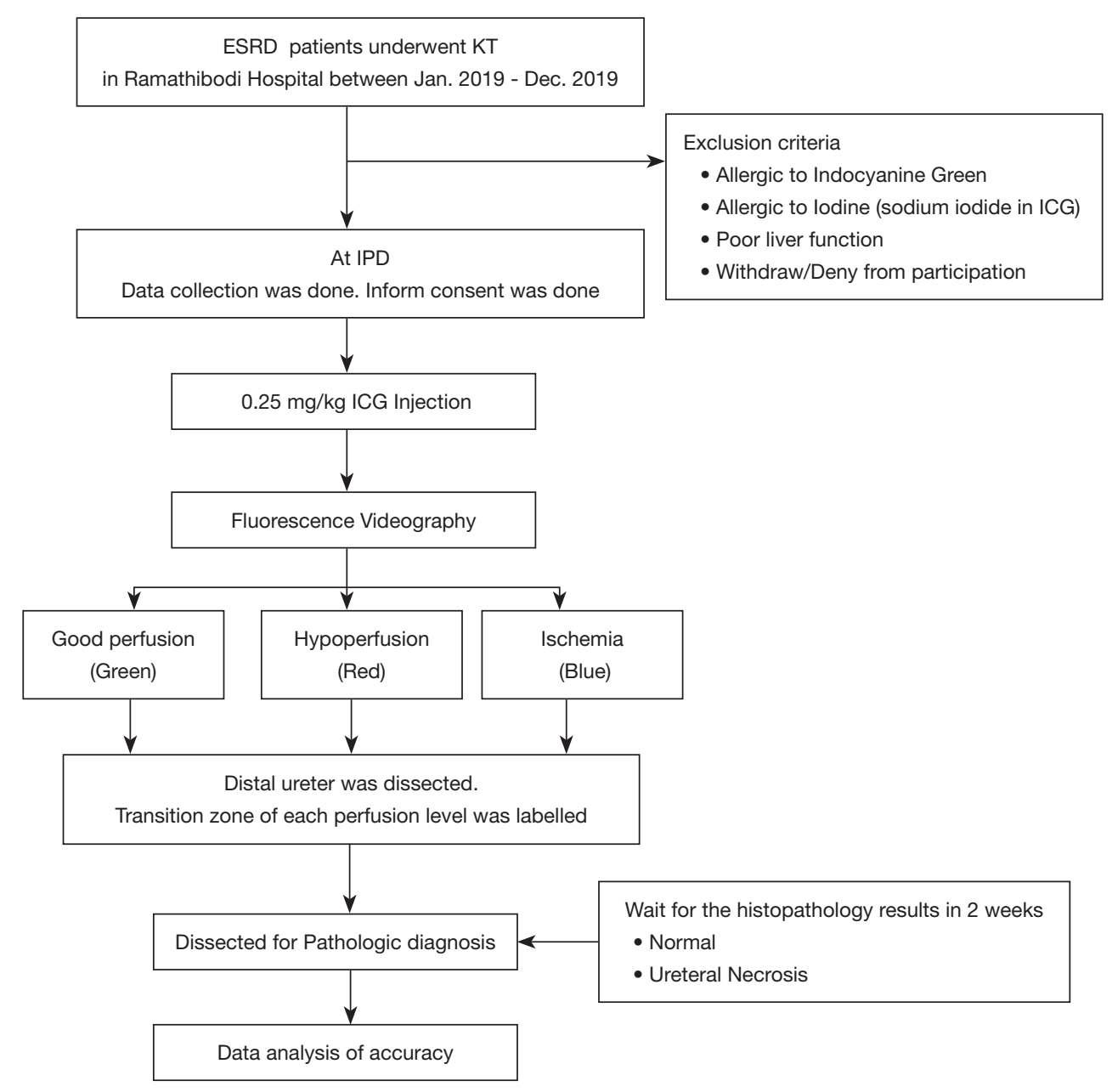

Figure 1 Flow chart of the study procedure.

18 years admitted to the hospital for DDKT. We excluded patients with history of ICG or iodine allergy, poor liver function, and those who refused to participate in the study. When the patients were admitted for the DDKT, written informed consent was obtained from all participants and patients' anonymities were preserved. We reviewed the database containing information on the patients. Baseline features and perioperative data including age, sex, cold ischemic time, and recipient warm ischemic time were collected.

The study flow diagram is shown in Figure 1. Patients who met the inclusion criteria underwent DDKT as a standard procedure. Kidney graft was prepared, preserving in Euro-Collins solution and renal vessels and ureter were identified. After that, kidney graft was perfused and vascular anastomosis was subsequently performed using external iliac artery and vein. Ten minutes after vascular anastomosis was completed, a single dose of ICG (Diagnogreen ${ }^{\circledR}$ Injection, Daiichi Sankyo Propharma, Japan) was injected intravenously. The dose of ICG was $0.25 \mathrm{mg} / \mathrm{kg}$ body weight $(13,17)$, and the maximum dose was $12.5 \mathrm{mg}$, which was decreased from the amount used in ICG videography for other indications based on renal function. Fluorescent videography (Fluoptic, Fluobeam ${ }^{\circledR} 800$ Clinical System, Parvis Louis Néel, CS 2005038040 Grenoble Cedex 9, France) was then used to evaluate ureter perfusion, and was shown as the spectrum of color along with the percentage of perfusion. Digital photographs and video recordings of the area were captured until $5 \mathrm{~min}$ after ICG injection. The picture with maximal perfusion, which was defined as the picture when the perfusion colour persisted, was used for the analysis. Quantification of perfusion was then performed on the saved images after completing the operation. The assessor was blinded from the histopathology result. 
All patients were performed antirefluxing extravesical ureteroneocystostomy using Lich-Gregoir technique. The ureter was anastomosed to the bladder mucosa using maxon 4-0. The seromuscular layer was closed over the ureter creating the tunnel with chromic 3-0. Foley catheter was placed for 7 days and ureteral stent was placed for 14 days. Perioperative outcomes were recorded, including time to visualize ureter perfusion, and ureter length. Adverse events from ICG were monitored during and after the procedure $(16,19,20)$.

On the basis of ICG images, segments of transplanted ureters were categorized as having good or poor perfusion. Good ureteral perfusion was defined based on results from ICG videography, and showed a perfusion percentage of over $25 \%$, corresponding to the colors green, yellow, and red. In contrast, a perfusion percentage less than $25 \%$ indicated poor perfusion, corresponding to the color blue (21). A single interrupted 5-0 Maxon suture was placed at the transformation point and the junction was marked between each percentage of perfusion $(75 \%, 50 \%$, and $25 \%)$ and cut separately for pathological examination. Tissue was then sent for histopathological analysis. Ureter segments were evaluated histopathologically using an electron microscope within 24 hours after surgery. All specimens were evaluated by an experienced uropathologist who had specialized in KT for over 5 years. The pathologist was blinded to the results of ICG videography, and histopathological results were reported as normal or ischemic ureter. An ischemic ureter was defined as the observation of multiple focal denudations of urothelial cells that were distinguishable from traumatic tissue injury.

The primary outcome was the accuracy of ICG fluorescence videography. The gold standard diagnostic tool used in this study was histopathology. The secondary outcome was the average ureter length that maintained good perfusion before performing ureteral reimplantation using fluorescent imaging. The length of the viable ureter was measured from the ureteropelvic junction to the distal cut ureter. Finally, we evaluated adverse events from ICG, which can include anaphylaxis, anaphylactoid reaction, significant nausea or vomiting, and dizziness $(19,20)$.

\section{Statistical analysis}

Due to this was an initial study of the test, only 10 patients were included into our study. Missing data of the test were not expected because of the cross-sectional study design. Data pertaining to baseline features of patients and the procedure were presented as percentage or mean \pm standard deviation (SD). Sensitivity, specificity, positive predictive value (PPV), negative predictive value (NPV), positive likelihood ratio (+LR), negative likelihood ratio (-LR), and accuracy were analyzed. The test of equality of area under the receiver operating characteristic curve was used to determine differences in terms of accuracy. Statistical analyses were performed using Stata version 14 , and $\mathrm{P}<0.05$ was considered statistically significant.

\section{Results}

Ten patients met the inclusion criteria and were therefore eligible for the study. Flow of participants is shown in Figure 2. Seven patients (70\%) were male, and mean age was 45.8 years, with SD of 5.55. Mean cold ischemic time was $1,057.1 \mathrm{~min}$, with SD of $239.54 \mathrm{~min}$, while mean warm ischemic time was $43.2 \mathrm{~min}$, with SD of $8.4 \mathrm{~min}$. Regarding the donors, 8 were male and 2 were female. Mean age of the donor was 29.2 years old, with SD of 14.46 years old. Details on demographic parameters and perioperative outcomes are shown in Table 1.

Thirty-one segments of dissected ureters from the 10 patients were evaluated and compared with a pathological diagnosis of ureteral ischemia. A representative image from ICG videography is shown in Figure 3. A diagram showing the results of ICG fluorescence videography for each patient is shown in Figure 4.

ICG videography had sensitivity, specificity, PPV, NPV, and +LR of $100 \%, 92.6 \%, 66.7 \%, 100 \%$, and 14 , respectively. Accuracy was $93.6 \%$ (Table 2). The area under the curve of ICG fluorescence videography was 0.96 (Figure 5). The average ureter length that maintained good perfusion was $14 \mathrm{~cm}$ from the ureteropelvic junction. Adverse events from use of ICG, such as anaphylaxis, anaphylactoid reaction, significant nausea or vomiting, and dizziness, were not observed. Regarding kidney graft function, one patient (number 5 in Figure 4) experienced vascular thrombosis leading to graft loss, and underwent nephrectomy at 26 days after the operation.

\section{Discussion}

The incidence of urinary leakage following KT in our hospital was reported as $4.4 \%$ (6). This complication is associated with significant morbidity (including prolonged hospital stay and graft loss) and mortality. Risk factors include graft devascularization during organ procurement, 


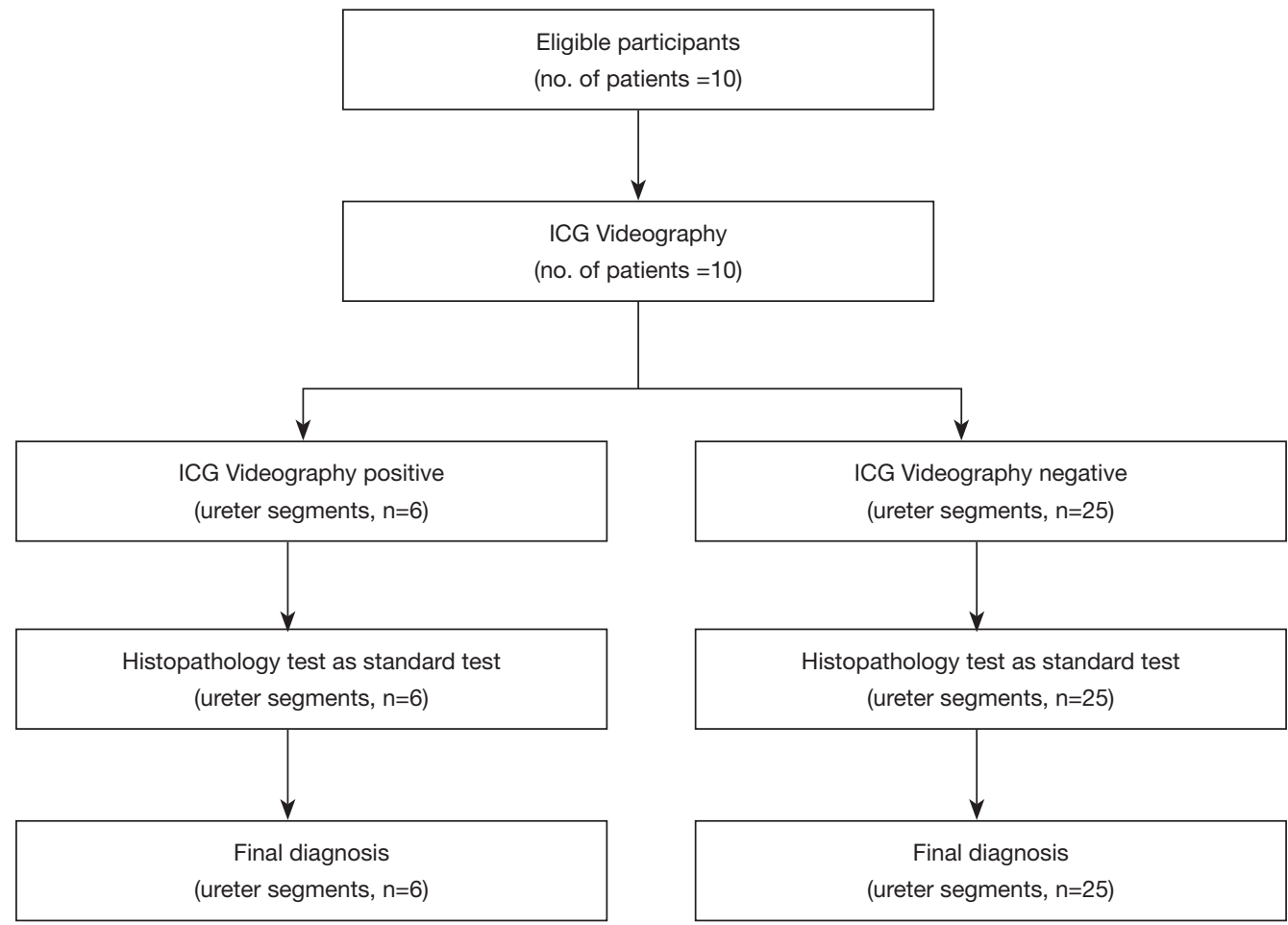

Figure 2 Flow of participants.

Table 1 Demographic data and perioperative outcomes

\begin{tabular}{|c|c|}
\hline Parameter & Total $(n=10)$ \\
\hline Male & $7(70 \%)$ \\
\hline Female & $3(30 \%)$ \\
\hline Age (years), mean \pm SD & $45.80 \pm 5.55$ \\
\hline Recipient warm ischemic time (min), mean \pm SD & $43.20 \pm 8.40$ \\
\hline Initial ureter length after vascular anastomosis $(\mathrm{cm})$, mean $\pm S D$ & $16.20 \pm 2.25$ \\
\hline Cut ureter before reimplantation $(\mathrm{cm})$, mean \pm SD & $11.15 \pm 1.25$ \\
\hline Dissected ureter for pathology $(\mathrm{cm})^{\star}$, mean $\pm \mathrm{SD}$ & $5.05 \pm 1.86$ \\
\hline Perfused ureter length at thigh $(\mathrm{cm})$, mean \pm SD & $12.75 \pm 1.49$ \\
\hline Time to visualize maximal ureter perfusion (sec.), mean \pm SD & $187.0 \pm 45.71$ \\
\hline Perfused ureter length at $T_{\max }(\mathrm{cm})$, mean $\pm S D$ & $14.0 \pm 2.13$ \\
\hline
\end{tabular}

*Dissected ureter for pathology was calculated from the difference in length between the initial ureter length after vascular anastomosis and the cut ureter before ureteroneocystostomy. SD, standard deviation. 


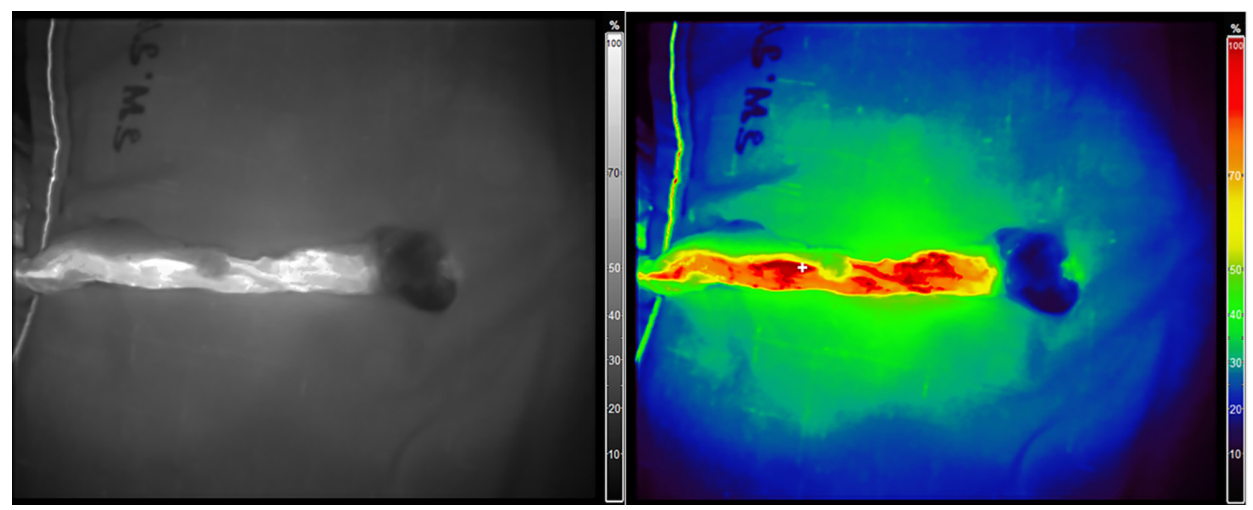

Figure 3 Imaging from paired structures identified in both monochrome (left) and multicolor (right) phases from before ureter anastomosis in the same patient.

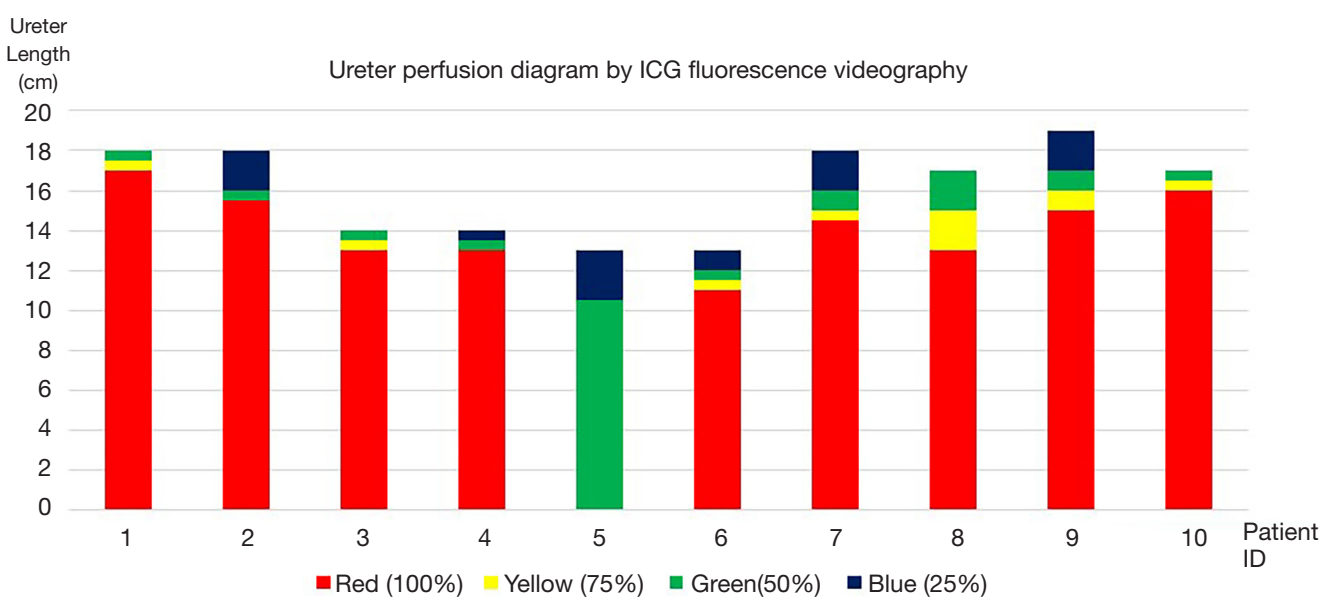

Figure 4 Ureter perfusion diagram by indocyanine green fluorescence videography.

Table 2 Sensitivity, specificity, positive predictive values, negative predictive values, and accuracy

\begin{tabular}{|c|c|c|c|c|c|c|c|c|}
\hline Pathology & \multicolumn{2}{|c|}{ ICG Videography } & Total & Sensitivity & Specificity & PPV & NPV & Accuracy \\
\hline Positive & 4 & 0 & 4 & $100 \%$ & $92.6 \%$ & $66.7 \%$ & $100 \%$ & $93 \%$ \\
\hline Negative & 2 & 25 & 27 & & & & & \\
\hline Total & 6 & 25 & 31 & & & & & \\
\hline
\end{tabular}

imprudent dissection, unskilled suturing, or prolonged cold ischemic time. Other factors that may contribute to development of urological complications after KT are graft-related, such as ureteral vascularization and arterial multiplicity. Distal ureteral ischemia and necrosis secondary to compromised blood supply are believed to be the main causes of early ureteral complications in most patients in the absence of technical difficulties during surgery. Transplanted ureters depend solely on blood supplied by the branches of the renal artery that traverse periureteric tissues. This area is also known as the golden triangle. Indeed, the importance of preserving periureteral connective tissue to prevent disastrous urinary complications is well documented (5,7-10). We believe that gentle manipulation of the ureter and 


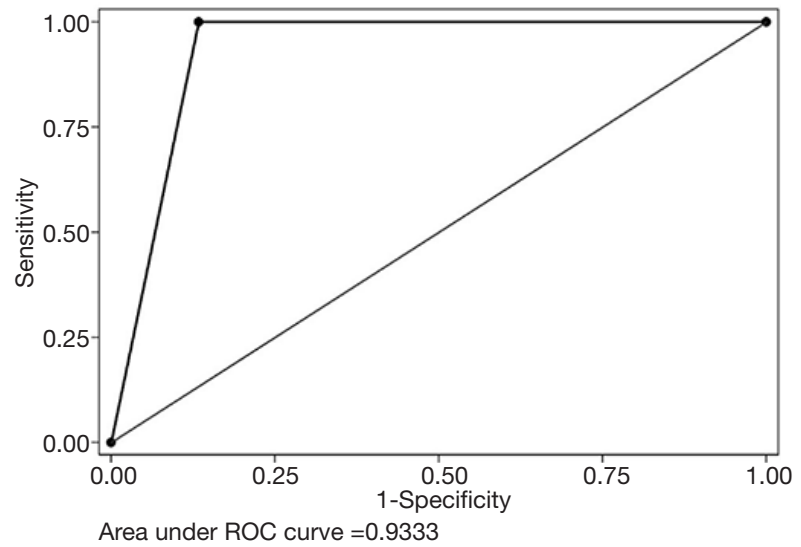

Figure 5 Receiver operating characteristic curve for predicting early ureteral ischemia using indocyanine green fluorescence videography.

adequate preservation of periureteral tissue, while properly maintaining the length of the ureter without tension, are of key importance. A ureter with ischemic appearance after reperfusion should be resected until a good area of perfusion is achieved (22-25).

In DDKT, it remains difficult to evaluate whether transplanted ureters are sufficiently perfused. In current practice, assessment of ureter viability depends on visualization by the surgeon, which is a subjective measurement and requires the surgeon to have sufficient experience. Furthermore, renal transplantation after ex vivo normothermic perfusion (EVNP) (26) was recently introduced in clinical practice using an EVNP circuit designed to deliver an oxygenated, warmed, red cell-based perfusate to the kidney. Creating a clear line of demarcation between a well-vascularized renal pelvis and proximal ureter and a distal ureter that appears to completely lack a blood supply, allows the ureter to be marked and transected at a point where the blood supply is deemed optimal. It should be noted that EVNP provides additional information on the adequacy of the ureteral blood supply before revascularization in the recipient (27). However, EVNP has long been costly and limited availability.

ICG is a molecule with mass of 776 Daltons that was approved for clinical use in 1959 by the Food and Drug Administration. It has been used in medicine since the late 1950s to assess liver function before major liver resections in cirrhotic patients (28). The applicability of fluorescence in the diagnosis of hepatic tumors such as hepatocellular carcinomas was initially described in a report from Japan.
Moreover, fluorescence has been extensively employed in gynecological, endocrinological, and colorectal surgeries (29-31). However, the applicability and potential advantages of using ICG fluorescence during organ transplantation are limited and incompletely understood. Fluorescent imaging can clearly visualize reconstructed vessels in living donor liver transplantations, kidney allograft perfusion, and renal vasculature after revascularization of transplanted kidneys. Rother et al., found that fluorescence angiography reflects preexisting morphological changes of the renal cortex which may serve as a method for the assessment of microperfusion of the kidney allograft (32). Siddighi et al. reported that intraurethral injection of ICG and visualization under nearinfrared light allow for real-time delineation of the ureter (33). Lee $e t a l$. found that intraurethral injection of ICG and subsequent visualization under near-infrared fluorescence facilitates robot-assisted ureteral reconstructions by aiding in rapid and accurate identification of the ureter and precise localization of the proximal and distal ureteral stricture margins (34).

The role of ICG fluorescence videography in intraoperative assessment of ureter perfusion after revascularization of a transplanted kidney, still remains questionable. Vignolini et al. reported the first preliminary experience with intraoperative ICG fluorescence videography for assessing graft and ureteral reperfusion during robot-assisted KT, and concluded that ICG provides a reliable assessment of graft reperfusion. However, larger studies are required to standardize the technique (35). Herein, we present our initial experience with ICG fluorescence videography for evaluating ureter perfusion during DDKT.

Our results showed that ICG fluorescence videography allows for high sensitivity and specificity in differentiating between normoperfused and hypoperfused segments of transplanted ureters. Compared with histopathology, the gold standard diagnostic method, the accuracy of ICG was over $90 \%$.

One patient in our cohort exhibited a large perfusion deficit in the kidney graft after initial positioning in the iliac fossa. After reperfusion, the graft was suspected of homogeneous impaired perfusion. However, this patient experienced vascular thrombosis that ultimately led to graft loss and was required to undergo nephrectomy within the subsequent 3 weeks. There were no complications with ICG injection or the video-imaging device. No adverse events from ICG were observed in our study. However, the safety of ICG cannot be concluded because our study had a 
small number of patients. Larger study with adverse event assessment will be required.

The strength of our study was that all participants underwent both the index test and pathological examination of ureters, which is considered the gold standard for diagnosis. These examinations eliminate verification bias. However, our study also had limitations. First, the number of participants was small and our study can be considered a pilot study. Larger studies are required to standardize the technique and to evaluate the association between perioperative parameters and acute ureteral ischemia. Second, we measured ureteral ischemia, which is considered a surrogate outcome rather than a clinical outcome of ureteral necrosis or anastomosis leakage. Further studies evaluating clinical outcomes are therefore warranted. Finally, regarding technical issues, the psychomotor skills of users, including the distance and angle from camera to targeted ureter, may affect the interpretation of results. Interobserver variation should also be further validated.

In our study, ICG fluorescence videography provided reliable and relevant additional information to surgeons for guiding intraoperative decisions in DDKT without adverse events, and should be used as an adjunct to clinical assessments in cases with ureters with an indeterminate state of perfusion.

\section{Conclusions}

ICG fluorescence videography is beneficial for the detection of early ureteral ischemia in DDKT patients with negligible complications because it is minimally invasive and displays high accuracy. However, further studies with larger numbers of patients and follow-up for clinical outcomes are necessary to further validate our results.

\section{Acknowledgments}

The authors thank The Ramathibodi Excellence Center for Organ Transplantation, The Division of Plastic and Maxillofacial Surgery, Department of Surgery, Ramathibodi Hospital, Mahidol University, Bangkok, Thailand. The authors would like to express sincere gratitude for major assistance with statistical analysis and valuable advice from Ms. Suraida Aeesoa. We thank Richard Robins, $\mathrm{PhD}$, from Edanz Group (https://en-author-services.edanz.com/ac) for editing a draft of this manuscript.

Funding: This research project was supported by the Faculty of Medicine, Ramathibodi Hospital, Mahidol University.

\section{Footnote}

Reporting Checklist: The authors have completed the STARD reporting checklist. Available at http://dx.doi.org/10.21037/ tau-21-160

Peer Review File: Available at http://dx.doi.org/10.21037/ tau-21-160

Data Sharing Statement: Available at http://dx.doi. org/10.21037/tau-21-160

Conflicts of Interest: All authors have completed the ICMJE uniform disclosure form (available at http://dx.doi. org/10.21037/tau-21-160). The authors have no conflicts of interest to declare.

Ethical Statement: The authors are accountable for all aspects of the work in ensuring that questions related to the accuracy or integrity of any part of the work are appropriately investigated and resolved. The study was conducted in accordance with the Declaration of Helsinki (as revised in 2013). The study was approved by the Committee on Human Rights Related to Research involving Human Subjects, Faculty of Medicine, Ramathibodi Hospital (No. MURA2018/405). Informed consent was taken from all individual participants and patients' anonymities were preserved.

Open Access Statement: This is an Open Access article distributed in accordance with the Creative Commons Attribution-NonCommercial-NoDerivs 4.0 International License (CC BY-NC-ND 4.0), which permits the noncommercial replication and distribution of the article with the strict proviso that no changes or edits are made and the original work is properly cited (including links to both the formal publication through the relevant DOI and the license). See: https://creativecommons.org/licenses/by-nc-nd/4.0/.

\section{References}

1. Cockwell P, Fisher LA. The global burden of chronic kidney disease. Lancet 2020;395:662-4.

2. Schena FP. Epidemiology of end-stage renal disease: International comparisons of renal replacement therapy. Kidney Int 2000;57:S39-S45.

3. Transplantation. GOoDa. World Health Organization collaborating centre on Donation and Transplantation: 
Centers for Disease Control and Prevention. 2020. Available online: http://www.transplant-observatory.org

4. Purnell TS, Auguste P, Crews DC, et al. Comparison of life participation activities among adults treated by hemodialysis, peritoneal dialysis, and kidney transplantation: a systematic review. Am J Kidney Dis 2013;62:953-73.

5. Slagt IK, Ijzermans JN, Visser LJ, et al. Independent risk factors for urological complications after deceased donor kidney transplantation. PLoS One 2014;9:e91211.

6. Jenjitranant P, Tansakul P, Sirisreetreerux P, et al. Risk Factors for Anastomosis Leakage After Kidney Transplantation. Res Rep Urol 2020;12:509-16.

7. Cullmann HJ, Prosinger M. Necrosis of the allograft ureter--evaluation of different examination methods in early diagnosis. Urol Int 1990;45:164-9.

8. Sinha M, Lewis MA, Riad H, et al. Complete necrosis of allograft ureter after cadaveric renal transplantation. Pediatr Transplant 2004;8:91-3.

9. Elkoushy MA, Andonian S. Campbell-Walsh Urology: Surgical, Radiographic, and Endoscopic Anatomy of the Kidney and Ureter. Campbell-Walsh Urology: Surgical, Radiographic, and Endoscopic Anatomy of the Kidney and Ureter, 2015:967-77.

10. Fjeldborg O, Kim CH. Ureteral complications in human renal transplantation. An analysis of 180 cases. Urol Int 1972;27:417-31.

11. Alander JT, Kaartinen I, Laakso A, et al. A review of indocyanine green fluorescent imaging in surgery. Int J Biomed Imaging 2012;2012:940585.

12. Panaro F, Benedetti E, Pineton de Chambrun G, et al. Indocyanine green fluorescence angiography during liver and pancreas transplantation: a tool to integrate perfusion statement's evaluation. Hepatobiliary Surg Nutr 2018;7:161-6.

13. Sekijima M, Tojimbara T, Sato S, et al. An intraoperative fluorescent imaging system in organ transplantation. Transplant Proc 2004;36:2188-90.

14. Gerken ALH, Nowak K, Meyer A, et al. Quantitative Assessment of Intraoperative Laser Fluorescence Angiography with Indocyanine Green Predicts Early Graft Function after Kidney Transplantation. Ann Surg 2020. [Epub ahead of print]. doi: 10.1097/ SLA.0000000000004529.

15. Holm C, Tegeler J, Mayr M, et al. Monitoring free flaps using laser-induced fluorescence of indocyanine green: a preliminary experience. Microsurgery 2002;22:278-87.

16. Cherrick GR, Stein SW, Leevy CM, et al. Indocyanine green: observations on its physical properties, plasma decay, and hepatic extraction. J Clin Invest 1960;39:592-600.

17. Hoffmann C, Compton F, Schafer JH, et al. Intraoperative assessment of kidney allograft perfusion by laser-assisted indocyanine green fluorescence videography. Transplant Proc 2010;42:1526-30.

18. Sawada T, Solly M, Kita J, et al. An alternative tool for intraoperative assessment of renal vasculature after revascularization of a transplanted kidney. Am J Surg 2010;199:e69-71.

19. Speich R, Saesseli B, Hoffmann U, et al. Anaphylactoid reactions after indocyanine-green administration. Ann Intern Med 1988;109:345-6.

20. Benya R, Quintana J, Brundage B. Adverse reactions to indocyanine green: a case report and a review of the literature. Cathet Cardiovasc Diagn 1989;17:231-3.

21. Moyer HR, Losken A. Predicting mastectomy skin flap necrosis with indocyanine green angiography: the gray area defined. Plast Reconstr Surg 2012;129:1043-8.

22. Buttigieg J, Agius-Anastasi A, Sharma A, et al. Early urological complications after kidney transplantation: An overview. World J Transplant 2018;8:142-9.

23. Buresley S, Samhan M, Moniri S, et al. Postrenal transplantation urologic complications. Transplant Proc 2008;40:2345-6.

24. Samhan M, Al-Mousawi M, Hayati H, et al. Urologic complications after renal transplantation. Transplant Proc 2005;37:3075-6.

25. Ooms LS, Slagt IK, Dor FJ, et al. Ureteral length in live donor kidney transplantation; Does size matter? Transpl Int 2015;28:1326-31.

26. Marshall MV, Rasmussen JC, Tan IC, et al. Near-Infrared Fluorescence Imaging in Humans with Indocyanine Green: A Review and Update. Open Surg Oncol J 2010;2:12-25.

27. Nicholson M, Hosgood S. Preoperative Assessment of Renal Transplant Ureteric Blood Supply Using Ex Vivo Normothermic Perfusion. Transplantation 2015;99:e166.

28. De Gasperi A, Mazza E, Prosperi M. Indocyanine green kinetics to assess liver function: Ready for a clinical dynamic assessment in major liver surgery? World J Hepatol 2016;8:355-67.

29. Boni L, David G, Mangano A, et al. Clinical applications of indocyanine green (ICG) enhanced fluorescence in laparoscopic surgery. Surg Endosc 2015;29:2046-55.

30. Diana M, Noll E, Diemunsch P, et al. Enhanced-reality video fluorescence: a real-time assessment of intestinal viability. Ann Surg 2014;259:700-7. 
31. Kudo H, Ishizawa T, Tani K, et al. Visualization of subcapsular hepatic malignancy by indocyanine-green fluorescence imaging during laparoscopic hepatectomy. Surg Endosc 2014;28:2504-8.

32. Rother U, Amann K, Adler W, et al. Quantitative assessment of microperfusion by indocyanine green angiography in kidney transplantation resembles chronic morphological changes in kidney specimens. Microcirculation 2019;26:e12529.

33. Siddighi S, Yune JJ, Hardesty J. Indocyanine green for

Cite this article as: Kanammit $\mathrm{P}$, Sirisreetreerux $\mathrm{P}$, Boongird S, Worawichawong S, Kijvikai K. Intraoperative assessment of ureter perfusion after revascularization of transplanted kidneys using intravenous indocyanine green fluorescence imaging. Transl Androl Urol 2021;10(6):2297-2306. doi: 10.21037/tau-21160 intraoperative localization of ureter. Am J Obstet Gynecol 2014;211:436.e1-2.

34. Lee Z, Moore B, Giusto L, et al. Use of indocyanine green during robot-assisted ureteral reconstructions. Eur Urol 2015;67:291-8.

35. Vignolini G, Sessa F, Greco I, et al. Intraoperative assessment of ureteral and graft reperfusion during robotic kidney transplantation with indocyanine green fluorescence videography. Minerva Urol Nefrol 2019;71:79-84. 